\title{
Study of the environmental influence on the dynamic behavior of adobe walls: preliminary test in laboratory specimens
}

\author{
Rick Delgadillo ${ }^{1}$, Giacomo Zonno ${ }^{2}$, Rubén Boroschek ${ }^{3}$, Paulo B. Lourenço ${ }^{4}$, Rafael Aguilar ${ }^{5}$ \\ ${ }^{1}$ Master' Student, Department of Civil Engineering, Pontificia Universidad Católica del Perú - PUCP, Lima, Peru. \\ ${ }^{2}$ Ph.D. Student, Department of Civil Engineering, Pontificia Universidad Católica del Perú - PUCP, Lima, Peru. \\ ${ }^{3}$ Associate Professor, Department of Civil Engineering, University of Chile, Santiago, Chile. \\ ${ }^{4}$ Full Professor, Department of Civil Engineering, ISISE, University of Minho, Guimarães, Portugal. \\ ${ }^{5}$ Associate Professor, Department of Civil Engineering, Pontificia Universidad Católica del Perú - PUCP, Lima, Peru.
}

\begin{abstract}
The shift of modal parameters induced by temperature and humidity effects may mask the changes of vibration properties caused by structural damage because the dynamic properties are often sensitive to changing environmental conditions. Furthermore, temperature and humidity are generally non-uniform and time-dependent variables, and therefore, their simple record in air or at a specific surface cannot be sufficient to obtain useful models to understand the relationship between the dynamic properties and environmental effects.

The present paper aims at presenting preliminary findings in the task of quantifying the effects of environmental conditions (variations in temperature and humidity) on the dynamic properties of earthen constructions with a laboratory test campaign. The first stage of the research consisted on the analysis of a real structural system and for this three 1:1 scale adobe walls were built in the laboratory. This stage considered the performance of a long-term monitoring program recording environmental conditions, the surface and inner walls variation of temperature and humidity and the dynamic behaviour of the walls. The second stage consisted on the understanding the correlation between dynamic properties and environmental parameters. In particular, linear auto-regressive models with exogenous variables (ARX) and multiple linear regression models (MLRM) were built and compared. The paper presents the results of the measurements and shows that is possible to distinguish the changes of dynamic properties due to environmental effects in adobe walls.
\end{abstract}

Keywords: Adobe masonry, Structural Health Monitoring, environmental effects, hygro-thermal monitoring, laboratory tests.

\section{INTRODUCTION}

Long term structural health monitoring systems are finding increased use in many fields, including preservation of historic structures. Many researches are being developed in the field of the Structural Health Monitoring (SHM) for implementing structural damage detection protocols and for this reason a diversity of damage detection methods are being implemented for different types of structures. Among them, vibration-based methodologies are prevalent and are being used more frequently for modern and historical constructions. The vibration-based method is used to monitor the structural condition and identify structural damage, because dynamic properties such as natural frequencies, mode shapes and modal damping are functions of the physical parameters of the structural mass, damping, and stiffness [1]. However, the vibration properties of real structures are not only affected by structural damages (earthquakes or by other types of dynamic loadings); environmental factors also cause changes in dynamic properties [2]. Several studies have reported that changes in structural responses due to temperature and humidity variation could be more significant than the changes due to structural damage [3]. In [4] the authors presented the variation of the dynamics properties due to the environmental effects of the Central Tower in Chile showing a decrease in the frequencies of about $0.7 \%$ when the external temperature is in the range of $20.5^{\circ} \mathrm{C}$ and $21.5^{\circ} \mathrm{C}$. The continuous monitoring system on the Dowling Hall Footbridge reported a variation of about $4-8 \%$ of natural frequencies due to a temperature range variation between -14 to $39^{\circ} \mathrm{C}$ [5]. It is accepted that the temperature can change the modulus of elasticity in an inverse relationship and also the boundary conditions can be dependent on the temperature variation [6]. Furthermore, the temperature distribution in a structure needs to be investigated because it is generally non-uniform and time-dependent. In [7] the researchers showed the correlation between environmental and internal temperature and dynamic properties of a RC slab and the non-uniform and time-dependent temperature distribution in the structure.

On the other hand, vibration-based structural health monitoring (SHM) techniques are being used increasingly for structural evaluation of historical buildings, such as bell tower [8], churches [9] and rammed earth structures [10]. This is due to its completely non-destructive character and for the respect of international standards to protect cultural heritage. [11] Shows a complete monitoring system for two historical structures with the objective of detecting structural damage and estimating the severity of damage. 
This paper presents an extensive study of temperature-humidity internal distribution of a full-scale adobe wall built in the laboratory with a specific focus on the environmental effects on the dynamic properties. The adobe wall was placed outside the laboratory and the dynamic parameters and environmental factors (internal temperature and humidity, air temperature and relative humidity) were monitored for more than four months. Correlations between modal frequencies and environmental parameters are investigated in detail. In addition, multiple linear regression models (MLRM) and linear auto-regressive models with exogenous variables (ARX) are established.

\section{METHODOLOGY}

Monitoring data were locally recorded and subsequently processed. For processing purposes, the authors have developed a code in LabVIEW [12] to automatically obtain the dynamic properties of the studied systems. Linear auto-regressive models with exogenous variables (ARX) and multiple linear regression models (MLRM) are developed in Matlab [13] and they are adopted to obtain correlations between environmental parameters and natural frequencies in the studied walls.

The dynamic properties are obtained with an automated procedure using the Data-Driven Stochastic Subspace Identification method together with a new automatic analysis process for cleaning the stabilization diagram and selecting dynamic properties with the application of soft and hard validation criteria [14] and the hierarchical clustering methodology [15]. Subsequently, an algorithm for the automatic choice of the most representative values of the estimated parameters is developed with the use of the modal shape complexity criteria.

To calculate predictions considering previous recorded data of the dependent parameters, dynamic autoregressive models were used. These models have the advantage of being generated rapidly, as they are obtained experimentally when the input-output relationships of the system can be identified [16]. Firstly, the ARX model was used and it consists in the description of the output as an Auto-Regressive variable and the input as an eXogeneous one [17]. In this case, the input of the model corresponds to the environmental parameters, while the output corresponds to dynamic properties such as, the natural frequencies, damping and modal shape. Subsequently, Multiple Linear Regression (MLR) was used and it is a statistical technique that can be used to analyze the relation between a single dependent variable and several independent ones [18]. In this study, regression analysis were developed from a set of dependent variables (natural frequencies) and a set of independent variables (environmental factors such as temperature and humidity). The main objective of regression analysis is to develop a model that, with an initial tracking period, provides a good fit between the observations (input) and the calculated values of the dependent variable provided by the model [19]. These are usually obtained through the least squares method, which minimizes the sum of the squared errors.

\section{DESCRIPTION OF EXPERIMENT}

Adobe blocks ( 320 × 220 x $120 \mathrm{~mm}$ ) were built and dried for seven weeks approximately. Subsequently, the full-scale wall was built in the laboratory and was continuously monitored for more than 4 months. The dimensions of the adobe wall are $1660 \times 2000 \times 220 \mathrm{~mm}$ and a concrete plinth was considered as foundation to avoid the filtration of water through ground.

\section{Equipment and test setups}

The temperature and humidity monitoring systems were designed to monitor the internal temperature and humidity of adobe walls and the air temperature and humidity. Internal temperature data of adobe walls were collected through a system of sensors type LM35 [20] and the internal humidity through a system of sensors type FC28 [21] (Fig.1a and 1b). The measurement range of both are from $-55^{\circ} \mathrm{C}$ to $150^{\circ} \mathrm{C}$ and $5 \%$ to $95 \%$ respectively. A UX100-011 HOBO digital temperature and humidity sensor [22] was chosen to monitor the air temperature and humidity (Fig.1c). Its air temperature range is between $-55^{\circ} \mathrm{C}$ to $150^{\circ} \mathrm{C}$ and relative humidity range is between $0 \%$ to $99 \%$ with a temperature resolution of $0.024^{\circ} \mathrm{C}$ and humidity resolution of $0.05 \%$. The LM35 and FC28 sensors were connected to two data acquisition devices, NI USB 6225 (16-bit resolution, 80 analog inputs and $250 \mathrm{kS} / \mathrm{s}$ maximum rate) and NI USB 6003 (16-bit resolution, 8 analog inputs) [23] (Fig.1d). Furthermore, the accelerometers installed on site were PCB 393B12 uni-axial sensors model with $10 \mathrm{~V} / \mathrm{g}$ sensitivity, with a frequency range of $0.15-1000 \mathrm{~Hz}$ and a weight of $210 \mathrm{~g}$ (Fig.2a). These sensors include a thermal jacket for major outdoor protection [24]. The accelerometers were connected to two multi-channel systems, cDAQ-9234 (24-bit resolution, $102 \mathrm{~dB}$ dynamic range and anti-aliasing filters) [25] (Fig.2b).

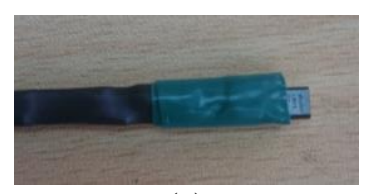

(a)

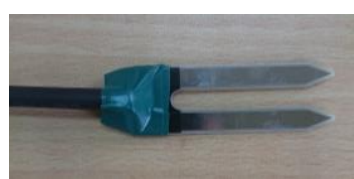

(b)

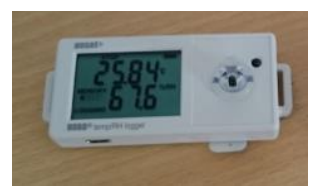

(c) 

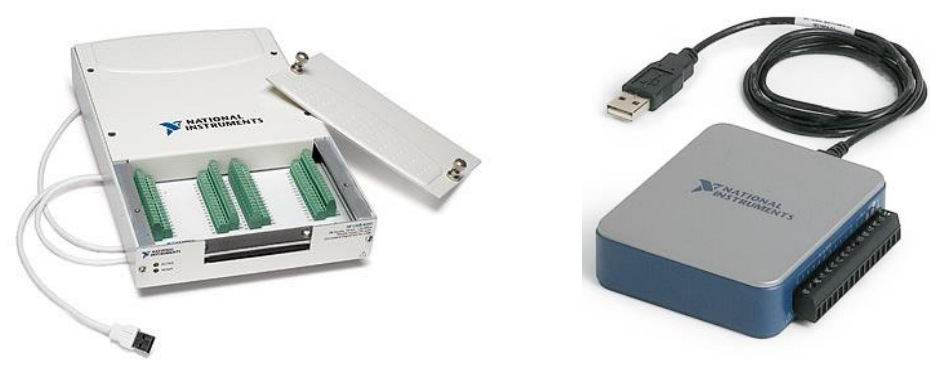

(d)

Figure 1. Environmental equipment (a) LM35 - internal temperature sensor (b) FC28 - internal humidity sensor (c) UX100-011 environmental sensor (d) NI USB 6225 and NI USB 6003 data acquisition devices

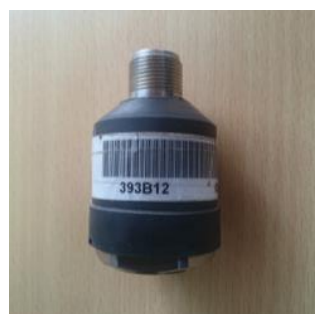

(a)

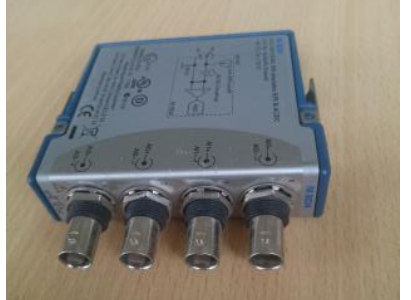

(b)

Figure 2. Acceleration monitoring equipment (a) PCB $393 B 12$ - accelerometer sensor (b) cDAQ9234 acquisition system.

To monitor the temperature and humidity inside the adobe wall, sensors were placed along four cross sections at the top, middle, down and foundation. Specific layouts of temperature and humidity sensors are shown in Fig. 3. Temperature and humidity sensors were placed in the plane of foundation to evaluate humidity gradients. The external environmental sensor was located close to the wall. The two visible transversal sections of the wall were coated to prevent moisture transmission in the East-West direction (black layers in Fig. 4). For a better quantification of the environmental conditions, the number of sensor were as follows: 10 temperature sensors ( 9 embedded sensors and 1 air temperature sensor) and 17 humidity sensors (16 embedded sensors and 1 relative humidity sensor). Data from internal and external sensors were acquired every 1 hour since September 2016.

The dynamic monitoring system consisted in placing three accelerometers for measuring out of plane (two sensors) and in plane (one sensor) behavior of the wall. Data from the accelerometers was acquired every 1 hour considering a $256 \mathrm{~Hz}$ sampling rate with 600 seconds of recorded data since September 2016. Fig. 4 shows the adobe wall and the continuous monitoring system installed.

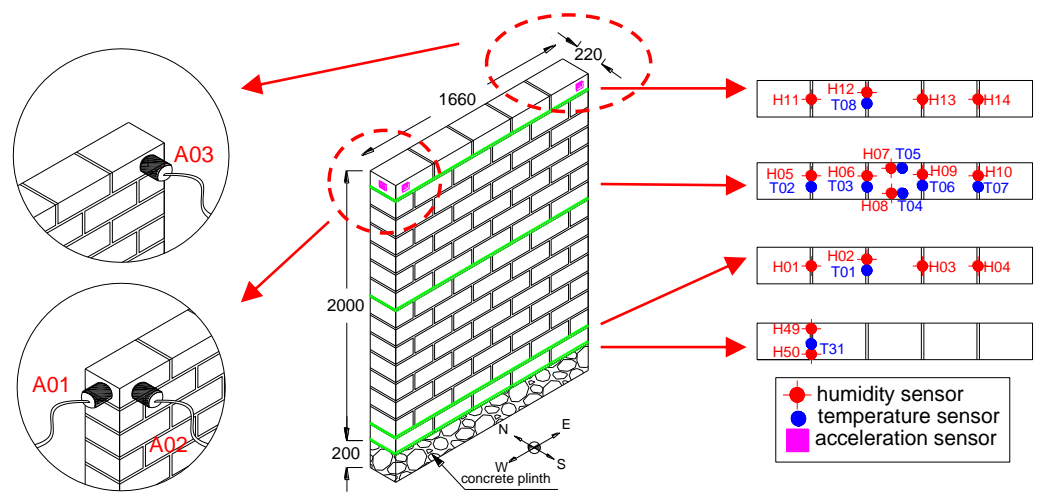

Figure 3. Sketch of the monitoring system with sensors positions of the adobe wall ( $A, H, T$ denote acceleration, humidity and temperature sensors respectively, dimensions in $\mathrm{mm}$ ). 

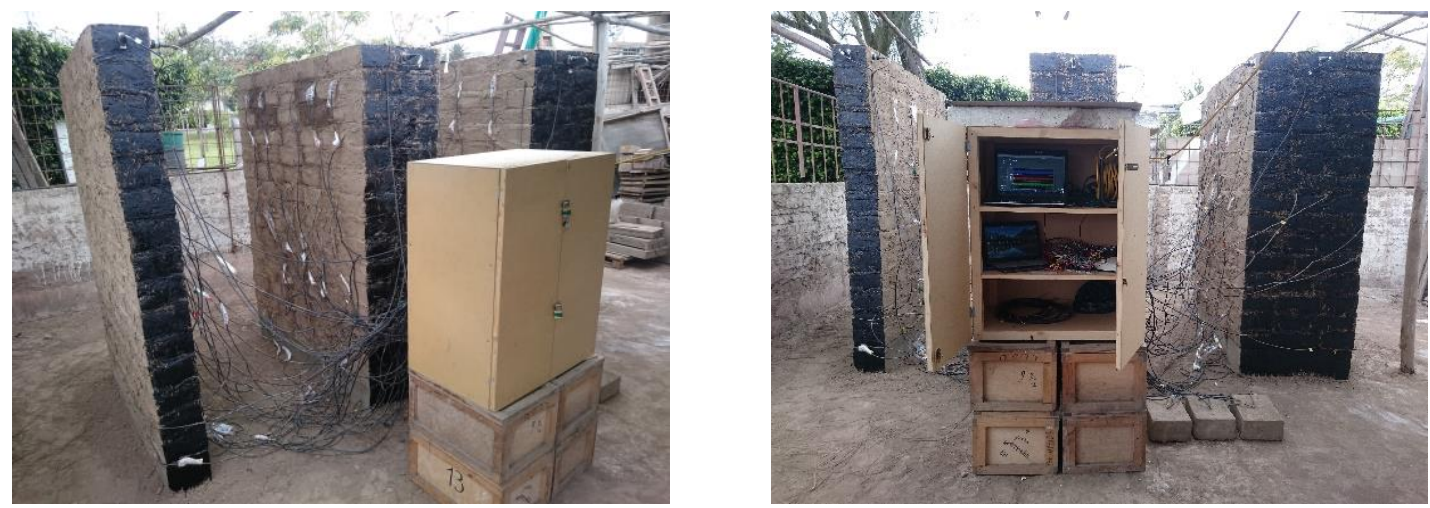

Figure 4: Place of installation and continuous monitoring center of three adobe walls.

\section{TEMPERATURE AND HUMIDITY INTERNAL DISTRIBUTION}

The temperature-humidity distribution in the adobe wall is non-uniform and time depending not only in the horizontal cross sections (in both the directions) but also along the height of the wall. In particular, the non-uniform distributions dependent on the several factors such as air temperature and humidity, solar radiation and the thermal inertia of earthen constructions. Fig. 5a shows the different internal temperatures recorded from the sensors T01 and T08, respectively at down and top sections. Furthermore, a similar behaviour is present with the other sensors (Fig. 5b). The significant differences of temperatures at the same time demonstrate the non-uniform temperature distribution inside the adobe wall during a day. A time lag of 3 hours between air temperature and temperature inside the wall was also registered, probably due to the adobe wall property to absorb solar energy and to transfer it later as heat, as referenced by [26]. Fig 5c shows the difference between the air temperature and the internal mean one, calculated by averaging the data of all the internal sensors.

The data of the humidity sensors shows the evolution of the moisture content since the walls' construction stage (Fig. 6). At the very beginning, a humidity close to $90 \%$ was recorded for the wet joints, and subsequently, the moisture content decreased until reaching a value of about $11 \%$ in the internal cross-sections. Due to the contact between concrete and adobe, the humidity at foundation is around of 7.2, which shows a no negligible influence between the two different materials. Furthermore, Fig. 6 shows the evolution of the air humidity and its daily variation.

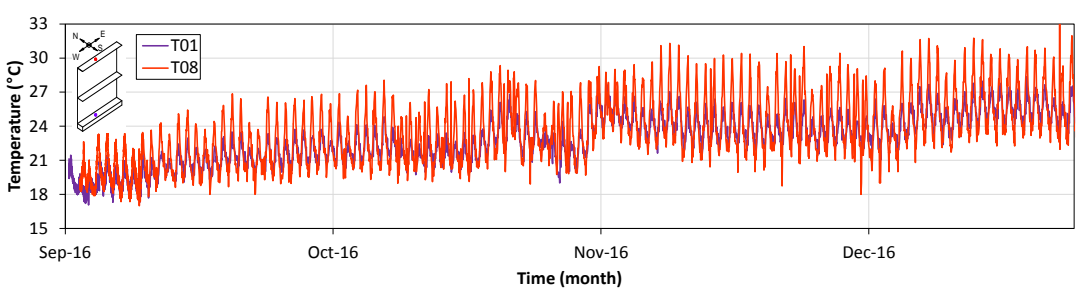

(a)

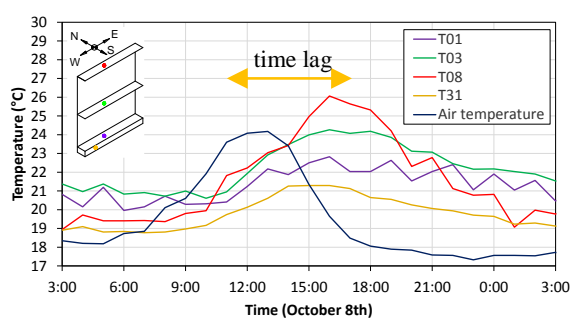

(b)

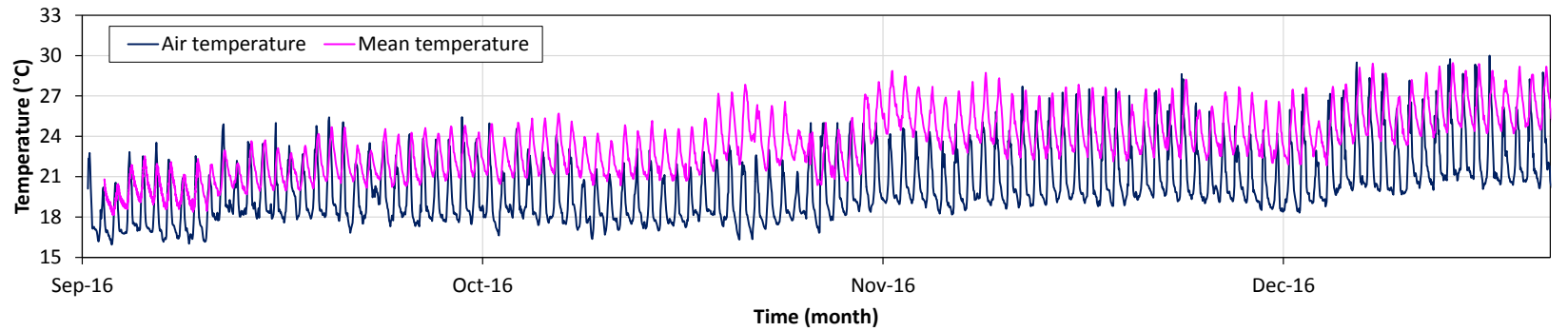

(c)

Figure 5. Temperature variations of the adobe wall (a) comparison between the temperature at top and down section (b) comparison between temperature in different points $(c)$ comparison between the air temperature and mean temperature 


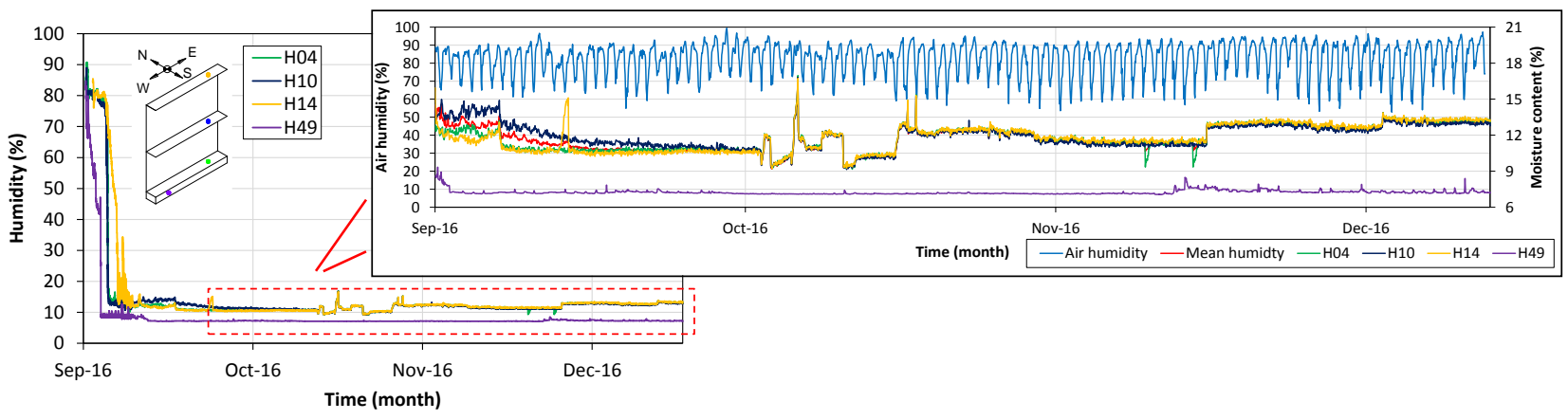

Figure 6. Humidity variation of the adobe wall.

To evaluate moisture and temperature variation inside the wall, the humidity and temperature at cross section at half height of the wall were analysed. Fig. 7 presents the temperature and moisture profiles of November 1, 2016 at 2:00 pm in the East-West section. There is a point where the temperature increases faster (the reverse case occurs with moisture), probably due to the solar radiation and the presence of the waterproof layers.

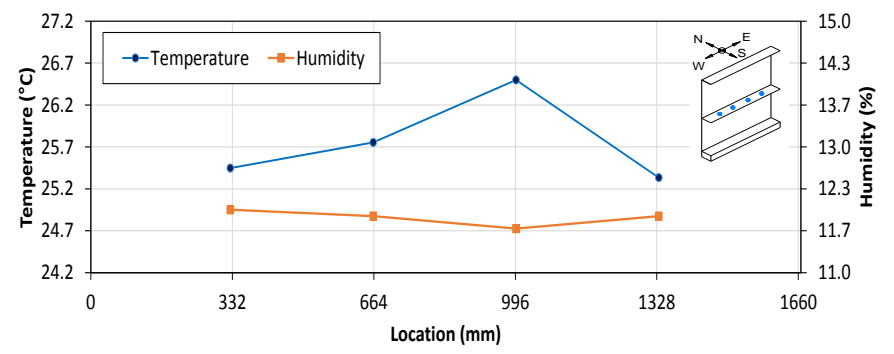

Figure 7. Internal temperature and humidity variation along the cross-section (November 1, 2016 at 2:00 pm).

\section{ANALYSIS OF ENVIRONMENTAL EFFECTS ON DYNAMIC PROPERTIES}

The wall was analyzed to quantify the effects of environmental conditions on the dynamic properties of earthen constructions. The first four frequencies were investigated and correlated with the environmental parameters and regression models were developed to obtain accurate prediction results.

\section{Variations of modal frequencies}

Fig. 8 shows the first four natural frequencies of the adobe wall. The results show a clear influence of daily temperature and humidity variations on modal frequencies. In the first month of data, it is evident the variation of the frequencies during the hardening process of the wall, and, in particular, the upward trend of the frequencies because the joints between the adobe blocks were hardening and, therefore, the rigidity of the wall tends to increase.

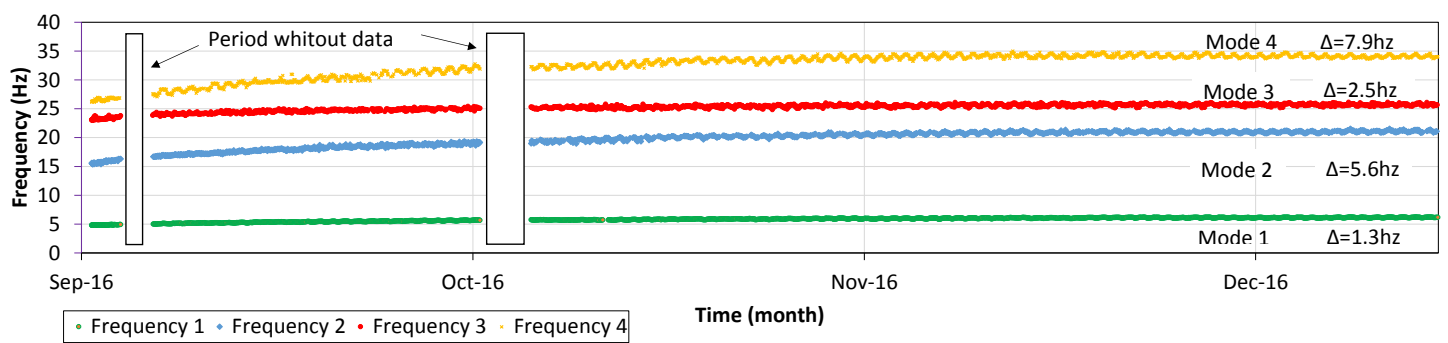

Figure 8. Variation of the identified natural frequencies during the monitoring period of the adobe wall.

\section{Correlation between identified natural frequencies and measured environmental parameters}

The external temperature and humidity and the internal mean temperature and humidity were considered to perform the correlation analysis with frequencies. Mean values are obtained by averaging the data from all the sensors placed along the three cross-sections at the top, middle and down (T01-T08) in the adobe wall. Fig. 9 shows the evolution in time of the frequencies and the environmental parameters from November 17 to November 25, 2016. Fig.9a shows that the modal frequencies change significantly with the variation of mean temperature and, moreover, each frequency decreases when the mean temperature increases, instead, the relationship with the air temperature does not show a similar behaviour with the presence of a time lag between frequency and measured air temperature. Fig. $9 \mathrm{~b}$ shows the comparison between the 
frequency and the air and internal mean humidity. Both humidities have a weak relationship with the frequencies. To quantitatively analyse the correlations between the monitored parameters, coefficients of determination $\left(R^{2}\right)$ were calculated and listed in the Table1. It is found that the $R^{2}$ between frequencies and internal mean temperature are larger than air temperature and humidity. Therefore, the relationship between modal frequencies and environmental parameters in earthen constructions cannot be properly developed using the air temperature and humidity.
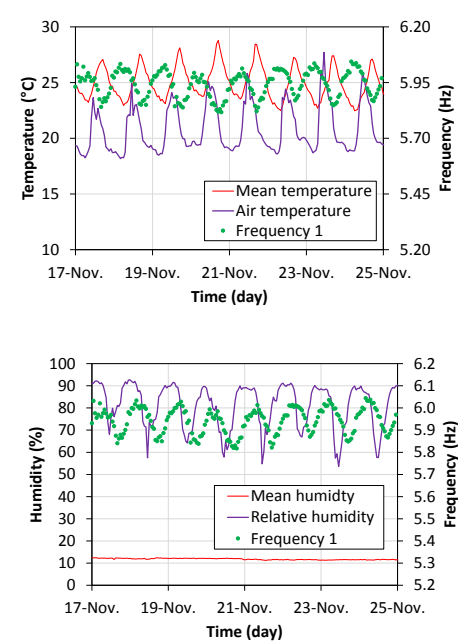

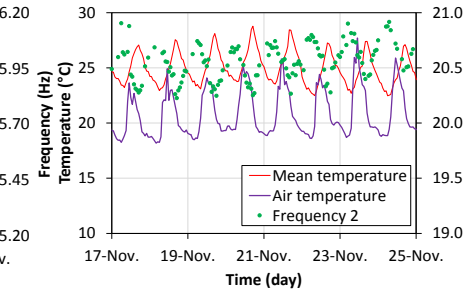

(a) Temperature and frequency variation

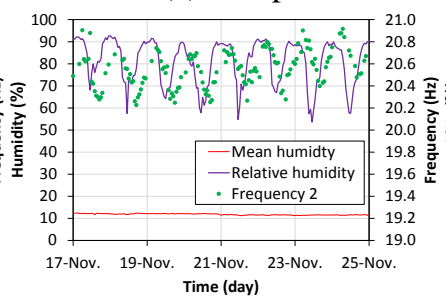

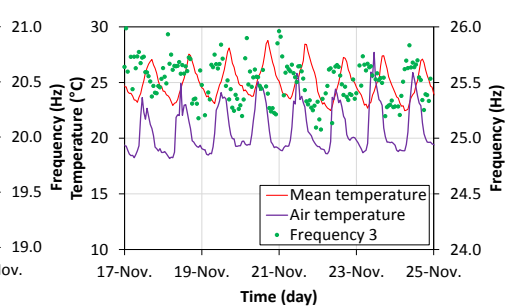
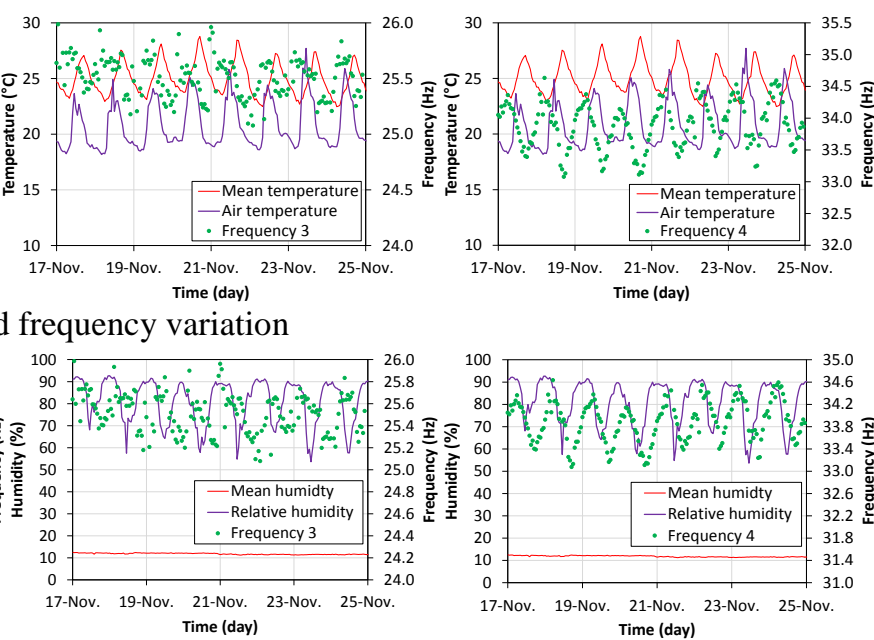

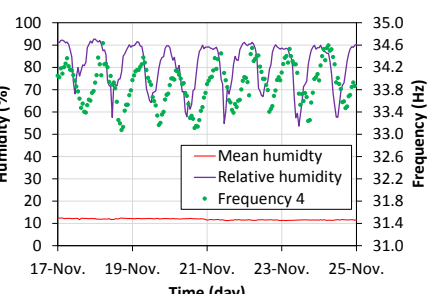

Time (day)

Figure 9. Correlation between modal frequencies and environmental parameters (a) Temperature and frequency variation (b) (b) Humidity and frequency variation.

Table 1. Coefficient of determination $\left(R^{2}\right)$ between modal frequencies and environmental parameters for wall type I.

\begin{tabular}{|c|c|c|c|c|}
\hline Environmental & \multicolumn{4}{|c|}{ Mode } \\
\cline { 2 - 5 } parameters & 1 & 2 & 3 & 4 \\
\hline Mean temperature & 0.88 & 0.81 & 0.16 & 0.82 \\
\hline Air temperature & 0.04 & 0.02 & 0.01 & 0.02 \\
\hline Mean humidity & 0.03 & 0.02 & 0.01 & 0.02 \\
\hline Air humidity & 0.12 & 0.14 & 0.10 & 0.15 \\
\hline
\end{tabular}

\section{Multiple linear regression (MLRM) and Linear Auto-Regressive model with Exogenous variables (ARX)}

A set of data from October 2016 to January 2017 was considered to develop the ARX and MLRM models and to predict the modal frequencies in function of the internal temperature. In the case of MLRM model, the internal temperature data recorded by all the sensors placed along the three-cross sections at the top, middle and down (T01-T08) in the adobe wall was considered, and in the case of ARX the internal temperature data was calculated by averaging the data from all the sensors of the same cross-sections. The input and output variables were divided into two subgroup, the first $50 \%$ of data was selected for estimating the parameters and the other $50 \%$ for the validation. MLRM and ARX models are developed considering the mathematical formulation given by Eq. (1) and Eq. (2) respectively. Fig. 10 shows identified and predicted frequencies in the monitoring period using the two statistical techniques (MLRM and ARX model). Subsequently, the coefficients of determination $\left(R^{2}\right)$ are calculated between the identified and predicted frequencies. In the case of ARX model are: $0.91,0.88,0.68$ and 0.89 and in the case of MLRM model are: $0.84,0.80,0.61$ and 0.80 for the first four frequencies of the adobe wall. This indicates that ARX can achieve a more favorable quantification of temperature influence on natural frequencies, even if the difference is small. However, the high coefficients of determination show a good fitting performance of both models that are able to predict the trend and magnitude of the identified modal frequencies.

$$
\begin{gathered}
f_{n}=\beta_{0}+\beta_{1} T_{01}+\beta_{2} T_{02}+\beta_{3} T_{03}+\beta_{4} T_{04}+\beta_{5} T_{05}+\beta_{6} T_{06}+\beta_{7} T_{07}+\beta_{8} T_{08} \\
A(z) y(t)=B(z) u(t)+e(t)
\end{gathered}
$$




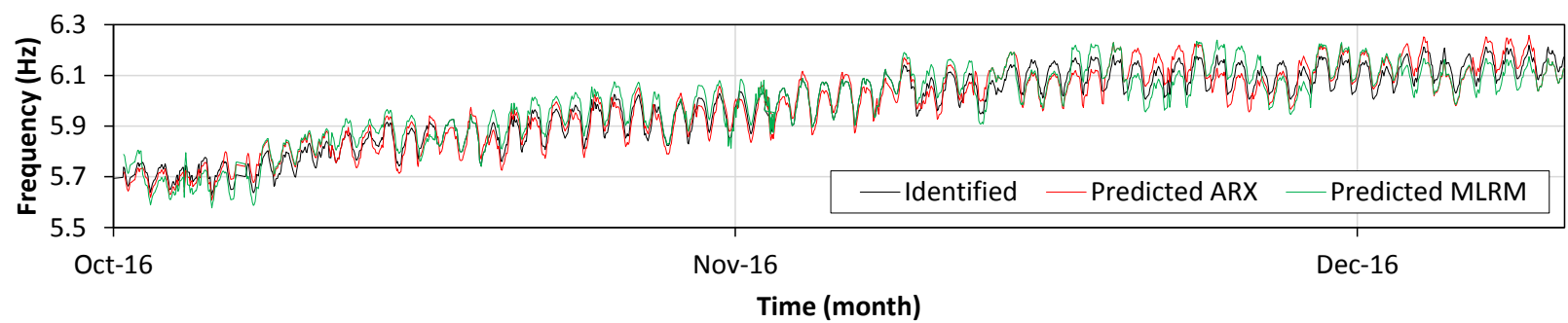

(a) First mode

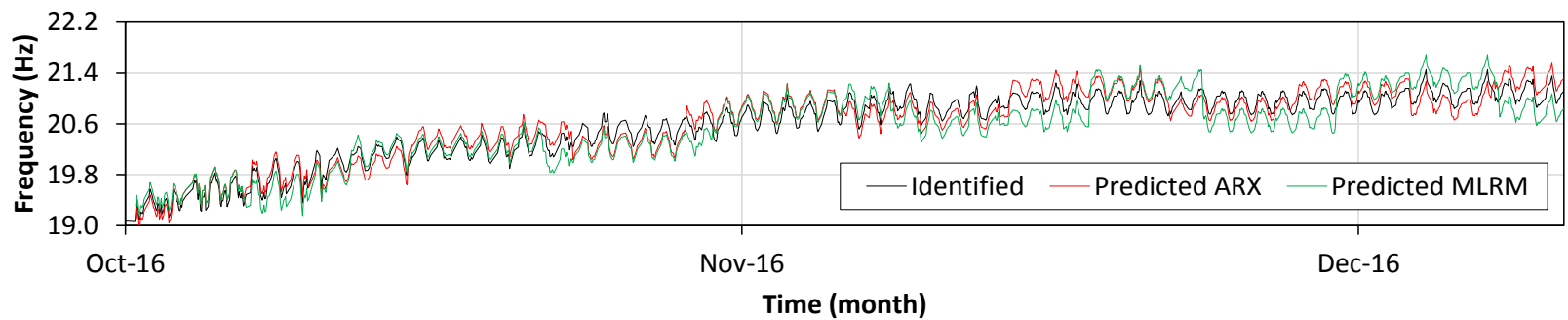

(b) Second mode

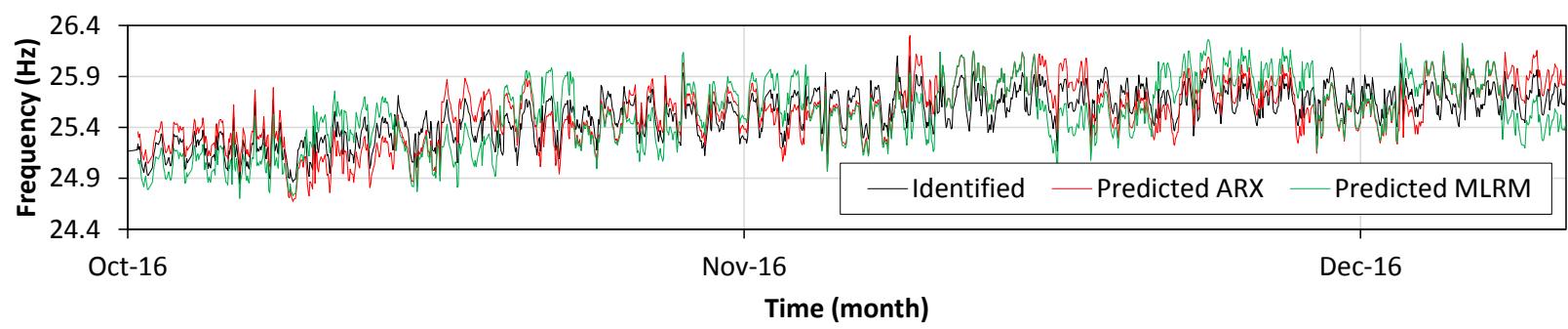

(c) Third mode

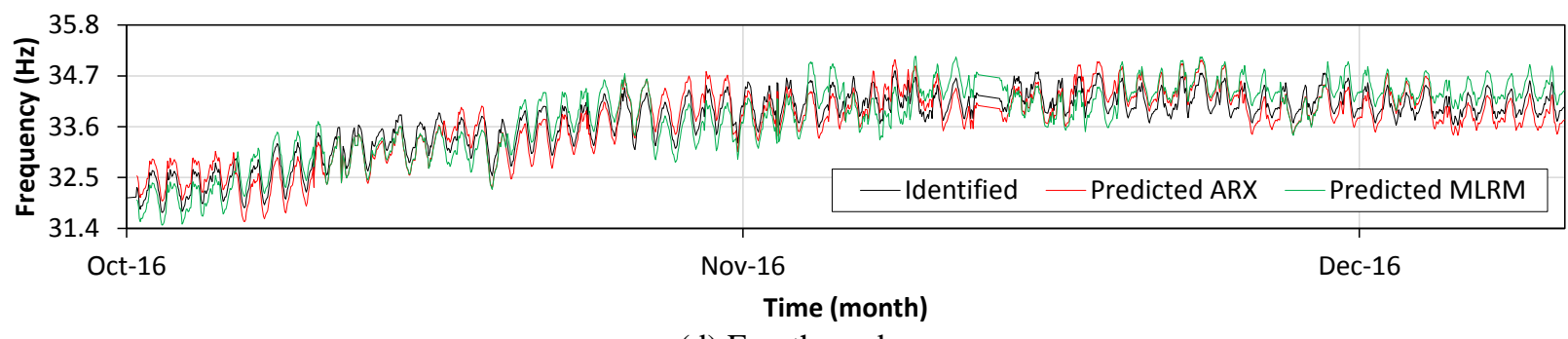

(d) Fourth mode

Figure 10. Identified and statistically predicted modal frequencies for the adobe wall.

\section{CONCLUSIONS}

In this paper, an adobe wall was built and placed outside the laboratory to continually monitor the dynamic properties and environmental conditions (temperature and humidity). The paper proposes to analyze the temperature and humidity nonuniform variation in the earthen constructions and to quantify the influence of environmental effects on modal frequencies through preliminary test in laboratory specimens. In contrast to the conventional studies that use only air temperature or temperatures at a few points of the structure, the paper aims to obtain the internal thermal distribution of the entire structure through continuous monitoring. Consequently, the relation between the modal frequencies and the temperature and humidity at the whole structure is established.

During the monitoring period, the variation range of first four natural frequencies of the adobe wall is between $1.3 \mathrm{~Hz}$ and $7.9 \mathrm{~Hz}$, while air temperature changes from $16^{\circ} \mathrm{C}$ to $27^{\circ} \mathrm{C}$. This frequency variation is mainly correlated with the hardening period of the wall.

The determination coefficients show that it is useful to consider the correlation between the frequencies and temperatures measured in the internal sections of the wall. Therefore, the non-uniform temperature distribution within an earthen structure is necessary to consider in the correlation between dynamic parameters and environmental parameters.

MLRM and ARX models were developed to correlate the modal frequencies with internal temperature. The proposed procedure makes it possible to obtain models with a good fitting performance. Finally, both models adequately predict the behavior of the modal frequencies under the effect of environmental conditions with coefficients of determination between 0.91 and 0.65 . 


\section{ACKNOWLEDGMENTS}

The present work was developed thanks to the funding provided by the program Cienciactiva from CONCYTEC in the framework of the Contract $\mathrm{N}^{\circ}$ 222-2015. The first author acknowledge FONDECYT for the scholarship in support of graduate studies (Contract $\mathrm{N}^{\circ}$ 027-2015-FONDECYT). The second author gratefully acknowledge ELARCH program for the scholarship in support of his PhD studies (Project Reference number: 552129-EM-1-2014-1-IT-ERA MUNDUSEMA21).

\section{REFERENCES}

[1] Zhou, G.D. and Yi., T.-H. (2004). A summary review of correlations between temperature and vibration properties of Long-Span bridges. Hindawai Publishing Corporation, Mathematical Problems in Engineering. vol. 2014, Article ID 638209,19 pages.

[2] Xia, Y., Hao, H., Zanardo, G. and Deeks, A. (2006). Long term vibration monitoring of an RC slab: temperature and humidity effect. Engineering Structures, vol. 28, no. 3, pp. 441-452.

[3] Yan, A.-M., Kerschen, G., De Boe, P. and Golinval, J.-C. (2005). Structural damage diagnosis under varying environmetal conditions-Part I: A linear analysis. Mechanical Systems and Signal Processing, vol. 19, pp. 847-864.

[4] Boroschek, R., Tamayo, F. and Aguilar, R. (2015). Evaluacion de los efectos ambientales en un edificio de media altura. XI Congreso Chileno de Sismología e Ingeniería Sísmica (ACHISINA), Universidad de Chile.

[5] Moser, P. and Moaveni, B. (2011). Environmental effects on the identified natural frequencies of the Dowling Hall Footbridge. Mechanical Systems and Signal Processing, vol. 25, pages 2336-2357.

[6] He, X. (2008). Vibration-Based Damage Identification and Health Monitoring of Civil Structures. PhD Thesis, University of California, San Diego.

[7] Xia, Y., Xu, Y.-L., Wei, Z.-L., Zhu, H.-P. and Zhou., X.-Q. (2011). Variation of structural vibration characteristics versus non-uniform temperature distribution. Engineering Structures, vol. 33, no. 1, pp. 146153.

[8] Ubertini, F., Comanducci, G. and Cavalagli, N. (2016). Environmetal effects on natural frequencies of the San Pietro bell tower in Perugia, Italy, and their removal for structural performance assessment. Mechanical Systems and Signal Processing, Mathematical Problems in Engineering. vol. 82, pages 307-322.

[9] Ramos, L., Aguilar, R., Lourenço, P. B. and Moreira, S. (2013). Dynamic structural health monitoring of Saint Torcato church. Mechanical Systems and Signal Processing, vol. 35, pages 1-15.

[10] Bui, Q.-B., Hans, S., Morel, J.-C. and Do, A.-P. (2011). First exploratory study on dynamic characteristics of rammed earth buildings. Engineering Structures, vol. 33, pp. 3690-3695.

[11] Morrison, T., (2008). Advanced numerical tool to analyze monitoring data. Master's Thesis, University of Minho, Portugal.

[12] National Instruments. (2016). LabVIEW 2015, United States.

[13]I. The MathWorks. (2012). MATLAB R2013a, Natick, Massachusets, United States.

[14] Boroschek, R. and Bilbao, J. (2015). Evaluation of an automatic selection methodology of model parameters from stability diagrams on a damaged building, 6th International Operational Modal Analysis Conference, IOMAC, Gijon, Spain, 12-14.

[15] Magalhães, F., Cunha, A. and Caetano, E. (2009). Online Automatic Identification of the Modal Parameters of a Long Span Arch Bridge. Mechanical Systems and Signal Processing, 23(2): 316-329 pp.

[16]Ljung, L. (1999). System identification: theory for the user. Prentice Hall, New Jersey.

[17]Peeters, B. and De Roeck, G. (2001). One-year monitoring of the Z24-Bridge: environmental effects versus damage events. Earthquake Engineering and Structural Dynamics, 30(2), 149-171.

[18] Johnson, R. A. and Wichern, D. W. (1992). Applied Multivariate Statistical Analysis. Prentice Hall.

[19] Magalhães, F. (2010). Operational modal analysis for testing and monitoring of bridges and special structures. Ph.D. thesis, Faculty of Engineering, University of Porto, Porto.

[20] National semiconductor corporation. (2016). Temperature sensor LM35. from national.com. http://www.fasttech.com.

[21]FC-28 Soil humidity detection sensor module. (2016). Humidity sensor. from amazon.com. http://www.fasttech.com.

[22] ONSET. (2015). Data logger. from ONSET.com. http://www.onsetcomp.com.

[23] National Instrument. (2016). NI USB-6225,6003. http://www.ni.com/datasheet/pdf/en/ds-10.

[24] PCB Piezotronics. (2016). Accelerometer 393B12. http://www.pcb.com/Products.aspx?m=393B12.

[25] National Instrument. (2016). Daq NI 9234. http://www.ni.com/datasheet/pdf/en/ds-316.

[26] Torres, I. and Peixoto de Freitas, V. (2010). The influence of the thickness of the walls and their properties on the treatment of rising damp in historic buildings. Construction and Building Materials, vol. 24, pages 1331-1339. 